\title{
Introduction: Working with the Grain? The Africa Power and Politics Programme
}

\author{
David Booth
}

Abstract At the heart of current policy thinking about Africa there is a significant knowledge gap concerning governance and development. This IDS Bulletin is concerned with what can be done about that, drawing on the initial experience of a new research venture, the Africa Power and Politics Programme. The APPP is committed to discovering forms of governance that work better for development than those prescribed by the current 'good governance' orthodoxy. It aims to do so chiefly by examining the range of post-colonial experience in sub-Saharan Africa focusing especially on under-appreciated patterns of difference in institutions and outcomes. This article explains the rationale of this approach and outlines the options which have shaped the programme's methods and concepts. $A$ central challenge has been operationalising the working hypothesis that institutions function better when they 'work with the grain' of the society which hosts them.

\begin{abstract}
1 Introduction
Governance reform in Africa has lost its way. Twenty years after 'good governance' moved to the centre-stage in international declarations, official aid policies and non-governmental advocacy alike, the results of efforts to improve the way African countries are ruled remain seriously insufficient. This refers not only to the high-level, headline-grabbing episodes that tend to dominate media coverage of the region, but also to more mundane aspects of the everyday exercise of power. Below the apex of the national political systems and behind the headlines, in most parts of sub-Saharan Africa most of the time, governance is failing to work for development.
\end{abstract}

More technically, not enough is being done by national governments, by local authorities or by anyone else to provide the elementary public goods that are key preconditions for progress in any poor market economy. ${ }^{1}$ From the facilitation of economic enterprise to the maintenance of social peace or the protection of public health, today's regimes perform badly. In quite a few cases, they do worse than they did in the stillremembered past. In most places, corruption is ingrained and routine. As a result, in the typical economy, there is some measure of economic growth, but the vital investments needed for this to be sustained and become transformative fail to take place. The better-off solve their livelihood problems privately, while for the majority, life remains harsh, troubled and short. Above all, the synergies between economic, social and political progress that are the key to genuine development are systematically blocked.

Everyone has their own view of who is to blame for this situation, and there is a correspondingly long list of obstacles to be overcome. These typically include both the vested interests of powerful elites in the continuation of the present arrangements, and the pusillanimity and mixed motives of the international community where Africa is concerned. These are important issues. However, the focus of this article is on none of these matters, but on something else - the elements of the situation that have to do not with power or ill-will, but rather with the lack of understanding and a shared inability to conceive alternative scenarios and pathways.

\subsection{A knowledge deficit}

At the heart of the current impasse in policythinking in Africa and about Africa, I believe 
there is - among other things - a significant knowledge gap. International policy towards subSaharan Africa has rested for a number of years on the notion that improved aid flows to the region can be traded for improved country governance. This idea meets the political needs of the aid lobby in the North, but is unrealistic in several ways. Among other things, it implies that someone, somewhere, knows how to bring about developmental governance, and this would be simple to achieve if only Africa's leaders would try harder. The truth is, however, that no one really knows how to build the type of governance that Africa needs. The forms of governance that might work better for development under the specific conditions yielded by African history and geography are not known. We know what is wrong, we know why things are not working, but we do not know for sure what would work better, even in broad and imprecise terms.

This lack of knowledge, or of empirically rooted understanding, extends beyond the policy worlds to the research community specialising in African affairs. It is, to repeat, not the only barrier to forward movement; but it certainly renders the tasks of challenging powerful vested interests and producing coordinated and enlightened action very much more difficult than they would otherwise be.

This article is concerned with whether anything can be done to address this particular part of the African development dilemma. It introduces an international research initiative called the Africa Power and Politics Programme (APPP), whose central purpose is to generate a body of new knowledge on the difficult question of the way forward in African governance.

\subsection{The Africa Power and Politics Programme}

The APPP is a five-year undertaking by a consortium of research organisations based in Ghana, Niger, Uganda, the UK, France and the USA (www.institutions-africa.org). Our declared aim is to identify forms of governance that would - if more widely adopted - work significantly better for development and poverty reduction than the arrangements currently in place. We are dissatisfied with the conventional appeal for 'good governance' and convinced by Grindle's $(2004,2007)$ argument that the priority is to identify solutions that are 'good enough' to meet the immediate challenges facing Africa's peoples. We aim to design and begin to carry out a programme of empirical investigation that will support theorising about what works better and why, filling a gap in both policy-thinking and mainstream academic literature on African development.

One of the points of departure of the APPP is that 'good governance' provides an inadequate agenda for Africa, because it contains a surfeit of purportedly universal notions about what is good which actually reflect certain rather specific features of the recent history of the West. We think it fails to reflect the more genuinely universal experience that institutions work better when they build on what exists, make use of indigenous institutional creativity or are otherwise rooted in their sociocultural context. They work badly when they rely heavily on the implantation, without major modification, of models that have worked well in other times and places (Shivakumar 2005; Hyden 2006, 2008).

We began by expressing this metaphorically. Thus, one of our initial 'hunches' or working hypotheses was that better results are obtained by economic and political institutions that 'work with the grain' of the host society. Elsewhere, we declared in favour of public action that is 'anchored in local realities'. In other terms, we were interested in how Africa's own institutional resources and historical legacies might be harnessed for developmental purposes, rather than sidelined or viewed merely as barriers to changes whose desirability has been defined $a$ priori. The first task we confronted as a programme was how to turn this set of issues into a feasible agenda of research.

The remainder of this article is concerned with three aspects of this challenge:

- The nature of the knowledge gap that needs to be filled;

- The programme's methodological options;

- Operationalising the notion of 'working with the grain'.

In each of these areas, I limit myself to summarising the choices we have made. A final section explains how these are reflected in the work of the programme as represented in the remainder of this IDS Bulletin. 


\section{What sort of knowledge gap?}

Some readers may be surprised or sceptical about the claim that there is a gap in knowledge, given the recent outpouring of relevant research in both institutional economics and political science. However, I would insist that existing research-based literature does not provide clear answers to the questions now being posed about Africa.

\subsection{Disaggregating Africa}

Some questions have no doubt been settled. On the one hand, the large literature based on regression analysis and cross-country statistics has helped to establish that 'institutions rule' when it comes to the major determinants of development performance, including the effectiveness of aid (Rodrik et al. 2004). It has been able to tell us that various institutional arrangements can perform certain essential functions - thereby placing a large questionmark over policy doctrines that prescribe only one basic way of doing things - what Evans (2004) calls 'institutional monocropping'. However, it cannot tell us which arrangements are right for which group of countries at which stage in their development process. Leading practitioners of this art are inclined to recommend historical case studies using timeseries data as the best way of handling these vital questions (Rodrik 2003; Kohli 2004). We agree.

On the other hand, the literature on Africa that sits squarely in this historical-institutionalist tradition has been preoccupied with the rather narrow question of what distinguishes African development experience from that of the rest of the world, or from the rest of the world as it now is. This was essential groundwork. Notably, the succession of political scientists who between the 1970s and 1990s adapted Max Weber's concept of patrimonial authority to the analysis of contemporary African state formation performed an important service in relocating African experience into the mainstream of comparative history (Eisenstadt 1972; Levine 1980; Médard 1982; Bratton and van de Walle 1997). The concept of neo-patrimonialism was useful in that it both identified a key common feature of post-colonial arrangements across the region, and took away the sense that African governance patterns are sui generis. Although, as it has passed into common use, this concept has acquired a baggage of negative connotations, neo-patrimonialism was and remains a helpfully universal and non-normative concept.

What is true, however, is that establishing the specificity of the post-colonial state in Africa has rather got in the way of some other tasks. One is the task of explaining the general pattern - since it ought not to be taken as explaining itself (Leonard and Straus 2003). The other is distinguishing between the relatively benign and the plainly regressive forms of the general pattern. Those who deploy the concept of neopatrimonialism do not generally imply or believe that it or its manifestations are the same everywhere. But with a few important exceptions (Berry 1993; Englebert 2002; Boone 2003), their work is not mainly or directly comparative across African countries or regimes. This has, undoubtedly, helped to create a gap in knowledge, and it is to this gap that the APPP is addressed. We argue that, when thinking about pathways towards development, it is worth distinguishing among the different forms that neo-patrimonial rule can take. We should at least consider the possibility that there are forms of the neo-patrimonial state that combine patronage politics with quite a high degree of developmental effectiveness, as recognised 20 years ago by Richard Crook (1989, 1990).

\subsection{Focusing on the right timescale}

In this respect, we are influenced by those like Khan (2006), Meisel and Aoudia (2008), Mick Moore et al. (Centre for the Future State 2010) and Levy (2010) who, like Grindle, question whether good advice on governance for development can be derived by fitting trend lines to large sets of cross-national statistical data. We even doubt the relevance of the excellent qualitative studies now appearing, which take on the broad sweep of institutional development in human history (Acemoglu et al. 2005; North et al. 2009). In the poorest countries of Asia and Africa, attention needs to be focused on immediate priorities and whether the standard, first-best institutional approaches are both practical and affordable. In general, pragmatic solutions that build upon what already exists are preferable.

With Crook and Khan, we suspect that, in Africa just as in Asia, patronage politics and corruption can work in ways that block provision of the public goods that are essential to reasonably inclusive economic growth and human 
development. But they can also work in ways that, while being second-best in many respects, are nonetheless consistent with rapid economic and social progress. With Moore (1994; Centre of the Future State 2010) and Granovetter (1985), we are persuaded that social networks and other informal arrangements can perform the role of enabling long-distance market transactions to take place efficiently - that is, fulfill the function that mainstream institutional economics assigns only to formal economic institutions. This leads to such questions as: is there a 'developmental neo-patrimonialism?? If so, what does it look like, at macro, meso and micro levels? And what are the preconditions for its emergence?

These are all comparative questions. They are not new. There is, in fact, quite a rich literature on comparative institutions and the state in both North-East and South-East Asia devoted to exactly these issues. This literature is the source of many of the ideas we now want to pursue in relation to African examples and issues. There are also some sets of Africa-Asia comparisons which explicitly pose questions for Africanists. A current programme led from the University of Leiden in the Netherlands (www.trackingdevelopment.net) had added very significantly to that literature by undertaking carefully paired comparisons between four African and four South-East Asian countries with a view to identifying the critical factors explaining the notable divergences in development performance that immediately come into view (van Donge et al. 2010).

As a rule, however, Asia/Africa comparisons highlight some missing elements in the African policy scenario or institutional framework, but shed little light on the question of what might be done about it. Generally, although the differences in historical legacies and cultural contexts between the regions are often exaggerated, particularly in Africa, direct transfer of Asian ways of doing things is not an option. There is therefore an acute need for comparative work that indicates missed opportunities and possible new avenues drawing on Africa's own experience. Our starting point in APPP is that this is an under-utilised research resource. We need to draw more comprehensively and systematically on Africa's own experience in order to think sensibly about the implications of the growing development gap with East Asia.

\section{Designing the research \\ 3.1 Empirical scope}

For the APPP, governance encompasses the exercise of power in the management of society's resources at all levels, from the offices of presidents to the back yards of urban neighbourhoods and the killing fields of local conflict zones. Our research does not limit itself to events and processes at the apex of state power, but aims to assemble a body of evidence on the full range of functions performed more or less badly by organs of the central or local state, from the administration of justice to the protection of natural resources or prevention of infantile dysentery.

There are two reasons for this choice. First, we wish to challenge conventional nostrums about good governance that are taken to apply comprehensively and with few reservations to today's development challenges in Africa. We therefore need evidence that is sufficiently crosscutting in terms of sectors or types of public goods to support a comprehensive response. Second, by including a variety of national and sub-national issue-areas in the scope of the programme, we also maximise our chances of discovering relevant empirical variation on which to test our emerging theories. The insufficiency of such variation has been and remains a challenge for anyone trying to answer the questions we are posing.

On this basis, we are undertaking empirical work in six Research Streams, designated as follows:

- Business and politics

- State bureaucracies

- Religion and the state

- Local justice and dispute settlement

- Parliamentarians

- Local governance and leadership.

In one case, 'Business and politics', work is under way in two distinct sub-streams, one concerned with general issues and one focused on cotton sector reforms in the Sahel, raising the effective number of streams to seven.

While in this respect we wish to cast the net wide, we also want to be able to generate some overarching conclusions about governance for development in Africa. 'Scaling up' from findings about, say, local administration of justice or politician-business interactions to general 
propositions about developmental governance is not going to be a matter of simple inference.

Nevertheless, we want the relationship between our evidence and our policy-relevant conclusions to be as compelling as possible. We have therefore tried to ensure that the work in each stream gives us real 'causal leverage' on our emerging hypotheses, so that the programme as a whole generates the elements of a policyrelevant middle-range theory. All the streams are looking for variations in the way different governance arrangements affect key intermediate outcomes that are known to be critical to final development outcomes. Across the streams, we are taking the adequacy of provision of essential public goods as a fulcrum for our empirical work and initial theorising.

\subsection{Method: systematic comparison and middle-range theory}

In thinking about the design of the APPP's empirical work, we have been consciously trying to map out a middle course, methodologically speaking, between the two extremes of multivariate statistical analysis requiring large datasets and intensive studies of single cases. ${ }^{2}$ In this, we have been assisted by having at our disposal a multidisciplinary team, including experienced practitioners of several methodological traditions. Within the team, we have strong advocates of the 'Manchester' tradition of ethnographic fieldwork and skilled practitioners of large- $\mathrm{N}$ multivariate analysis as well as advocates of the middle way represented by a systematic approach to small-N comparative studies.

We agree that so long as our theoretical propositions remain largely undeveloped, we need a relatively inductive, exploratory approach. Statistical testing would therefore be inappropriate even if relevant datasets were available or could be affordably generated. Additionally, the subject matter of neopatrimonial governance does not lend itself to standardised measurement. Neo-patrimonial states are said to be hybrids of formal legalbureaucratic structures and informal, patrimonial, arrangements, so it is the variations among such hybrids that interest us. There has to be a concern that any standardised indicators of institutional variation that might be devised would, like those currently available, only capture differences in the formal façade of what happens.
We also have a consensus that we want to go beyond the traditional anthropological monograph approach and its modern variants, where a single local case study or a loosely linked set of such studies provides the sole basis for theory development (Olivier de Sardan 2005). Experience suggests that with such an approach it is possible at most to shed doubt on some prevailing theory or picture of reality.

Monographic approaches do not serve well the development of new causal theories, and this programme is an opportunity to show that it is possible to do better, without compromising on the intensity and quality of the required fieldwork.

An attractive option is, therefore, what is provided by the major strand of methodological thinking in comparative politics and historical sociology which has emerged in recent decades in opposition to the mainstream quantitativism. The major figures in this stream, such as Collier (Collier et al. 2004), Ragin (1987) and Gerring (2007), provide a clear and cogent prospectus to which we are generally attracted. The common elements are a systematic approach to the selection of cases for comparative study, making use of small sets of theoretically interesting variables, and employing complementary techniques of within-case comparison and causal 'process tracing' to buttress and inform the cross-case analysis. There is a strong case for thinking that this style of research is not only good for theory building, but particularly suited to the type of middle-range theorising that policymakers appreciate (George and Bennett 2005). The full prospectus has requirements which we have struggled to meet but continue to treat as the relevant standard to which to aspire.

One of the challenging steps, in practice, has been to arrive at a sufficiently plausible set of explanatory variables with which to approach case selection. We have been eager to give an operational meaning to our initial hunch about 'working with the grain'. We have been keen to articulate what we think are the significant differences among Africa's neo-patrimonial regimes. But this has been a major research task on its own. We have had not just to ransack what we think we know about the facts. We have also had to go back to basics conceptually, and find our way around some sticky controversies which commonly divide researchers in African 
development studies. Through a combination of empirical and conceptual investigation, however, we are now in a position where some major issues can be considered clarified, if not settled.

\section{Beyond metaphor: operationalising the 'grain' hypothesis}

The idea of 'working with the grain' is powerfully expressive in English for anyone who has some experience or carpentry or wood-working of some kind. But for anyone whose practical experience of carpentry is limited, it is liable to confusion with metaphors other than the one intended. ${ }^{3}$ The same applies, to some extent, to the notion of 'anchorage' when disconnected from experience with ships, boats or hot-air balloons. Anyway, metaphors are not scientific concepts. An important part of the intellectual challenge posed by the programme has been to determine what kinds of concepts are good for formulating testable and potentially policy-relevant propositions along the lines suggested by these metaphorical statements of our working hypothesis.

\subsection{From public goods to political economy}

An important first step in that direction was the decision to focus research in all of the streams on major deficits in the provision of key public goods. As well as concentrating attention on what many specialists would accept as a critical intermediate variable in development processes, it allowed us not to be distracted by discussions about the validity of the standard final outcome measures, about whether the Millennium Development Goals set an appropriate standard for Africa, and so on. Not less importantly, it helped us to incorporate into our thinking concepts and modes of analysis, which have been used in other connections to explain patterns of public goods provision and under-provision, notably the various branches of rational-choice, social-mechanism and game theory (Ostrom 1990; Olson 1993; Hedström and Swedberg 1998; Sandler 2001). In this way, APPP has arrived at a position where its empirically grounded propositions are informed by a much wider field of general scholarship in the social sciences than any of us anticipated at the outset.

In a number of our research streams, asking questions about unresolved collective-action problems in relation to particular public goods has helped us to think about one basic sense in which institutions need to be anchored in local realities. Institutions which overcome the key bottlenecks in public goods provision will be ones that by accident or design address the relevant collective action problems. In contrast, institutions that have been designed elsewhere or with little or no connection to the specific factors in play will be unlikely to meet the real needs of the situation. The operational form of the hypothesis then becomes: public goods delivered better when institutions are shaped in such a way as to address the actually prevailing collective-action problems, and worse when they are imported from outside this local reality.

The problems to which this thinking is applicable are not just local. For example, a disciplined public bureaucracy can be considered as an under-provided public good, subject to the 'tragedy of the commons' type of social action dilemma. This helps to focus thinking on the conditions under which an African political leadership would be motivated to protect this public good and to set limits to the bureaucratic equivalent of overgrazing the range-lands, a different and better question than how performance against standard yardsticks of good governance may be expected to improve. The hypothesis becomes: the public good will be better served when it becomes of interest to the political leadership to impose limits on socially destructive behaviours, and worse when any such limitations (e.g. 'zero tolerance of corruption') are promoted independently of elite interest calculations (e.g. as donor conditionalities).

\subsection{The place of culture}

However, our hypothesis is not just about the public choice aspect of local anchorage. It is also about one of the conditions under which institutional choices that have a problem-solving potential are also capable of being understood, adopted and supported by the people that are involved in them. What else then is conveyed by 'working with the grain'?

A good first answer to this question is that solutions which work tend to be culturally embedded. This was the idea pursued in Tim Kelsall's article 'Going with the Grain in African Development?’ (Kelsall 2008). The article interpreted the grain metaphor in what is probably the most straightforward way, where the grain refers to some of the more widely 
observed features of the social fabric of subSaharan African societies. It identified a core set of beliefs and values - concerning power, accountability and social morality - that have proven extremely durable and remain powerful drivers of behaviour. Development efforts, the argument went, should stop treating these cultural elements as problems and start harnessing them in practical ways.

The idea of building on the extant notions of moral obligation and interpersonal accountability in the region, as Kelsall put it, remains part of the APPP vision. Aspects of the idea have been vigorously questioned (Olivier de Sardan 2008). However, we have quite a broad consensus around the original proposition as qualified and refined in the following three ways.

First, we must be wary of facile and old-fashioned assumptions about culture and its relationship to behaviour. On a theoretical level, we tend to agree with Swidler in seeing the causal role of culture 'not in defining ends of action, but in providing cultural components that are used to construct strategies of action'. So culture shapes action only insofar as the available cultural 'repertoire' limits the feasible action strategies (Swidler 1986). From a methodological point of view, we believe the relevant cultural components need to be uncovered empirically and not assumed.

Second, working with the grain should not mean making unproven claims about shared values (e.g. within ethnic groups) in explaining behaviour when more parsimonious and easily demonstrated explanations are available. In this sense, we have drawn lessons from the insights into voting and collective action among people of similar or different ethnic backgrounds produced by Daniel Posner and his colleagues (Posner 2005; Habyarimana et al. 2009).

Finally and importantly, while rational choice analysis provides a healthy antidote to premature invocation of explanations in terms 'shared values', 'ethnic community' and suchlike, it may not provide a comprehensive alternative. As Kelsall (2009) has shown, contextually modified game-theoretic concepts can be made to illuminate a wide range of social situations in ways that are potentially highly relevant to APPP's theory-building effort. ${ }^{4}$ However, this does not mean that shared values have no role to play in explaining significant differences in outcomes. For example, the finding that some Tanzanian villages solve difficult problems of collective action while others, similarly placed, do not, may only be explicable with reference to the observation that in some of the former cases, villagers are members of a single church. They have shared moral commitments which are able to be mobilised.

In a broadly similar vein, Greif (2006) provides a game-theoretic account of why institutional elements 'inherited from the past' are likely to be useful in developing ways of addressing collective action problems. Creating new institutions from scratch is simply too costly in terms of the bargaining, coordination, search and learning costs. Attempts to do so, for example by importing 'best practices' from the outside, typically fail. An implication is that successful institutions are typically hybrids of 'imported' and 'local' elements (which is not to imply that all hybrids are successful).

The programme hypothesis about working with the grain thus translates as follows. The institutions that will work best for public goods provision and development in the African context are ones that, by design or otherwise, have a local problem-solving character and build on relevant components of the available cultural repertoire, whether in the form of extant beliefs or values or in the form of widely recognised behavioural templates.

\subsection{Implications}

To the extent that the research confirms this hypothesis or a further refinement of it, what are the implications for policy? Answering this question entails thinking about how the behaviours of donors, governments and other influential actors might allow more space than they do at present for both the problem-solving arrangements and the cultural borrowing (or institutional hybridisation) that we find to be too often missing. This is bringing us hard up against the political economy of the aid relationship itself, and the ways in which it currently shapes the environment in which institutional choices are made or avoided. The policy messages that are likely to come out of the research as a whole seem likely to centre on this aspect. 


\section{What the research is telling us}

The contributions to this IDS Bulletin illustrate further how the programme has arrived at these positions. At the same time, they show how our core hypotheses are being articulated and used to interrogate the evidence on particular topics.

Five articles stem from our largest stream, on Local Governance and Leadership, and two provide overviews. The theory-oriented contribution by Booth brings out the way differences among types of regime and forms of aid affect three proximate determinants of the quality of public goods provision. Olivier de Sardan then sets the scene with particular reference to Francophone West Africa. He shows that no less than eight 'modes of local governance' are relevant to the issue of public service delivery, the typical pattern being codelivery involving players operating in at least four of these modes.

Three articles report country findings. Olivier de Sardan analyses evidence from three small towns in Niger showing how some key bottlenecks in public goods provision are addressed and others not. Cammack's contribution presents equivalent findings from Malawi. Although these two country studies place emphasis in different places, they coincide with each other and with Booth's overview in showing that the critical factors include the way provider disciplines are affected by the prevailing politics and the extent to which problem-solving collective action is feasible within the local governance system. Workman extends

\section{Notes}

* This article is the product of collective efforts and a rich ongoing discussion within the Africa Power and Politics Programme. However, since we agree on some issues and agree to disagree on others, I assume responsibility for the judgements expressed, including those on the general orientation of the programme and its emerging findings.

1 We give 'public goods' a relatively inclusive meaning, so that it refers not just to goods which are under-supplied by private action because their benefits spill over to those not this kind of thinking to the co-production of public goods between a municipal council and interestbased associations in Sierra Leone, identifying a particular kind of reciprocity between the partners as a key success factor.

The article by Grook, Asante and Brobbey reports on the main study undertaken within the Local Justice and Dispute Settlement stream. The study speaks strongly to the theme that the best forms of public goods delivery are practical hybrids, drawing on both modern professional standards and local cultural repertoires.

The final two articles, from the Business and Politics stream, offer a comparative synthesis and a country study for Malawi. The analysis presented by Kelsall makes the case for revisiting the orthodox view of the relationship between neo-patrimonial politics and country economic performance. As Cammack then explains with reference to three phases in Malawi, regimes differ in the ways they generate and use economic rents, with significant implications for the role played by national economic technocracies. With their attention to within-Africa differences in regime performance and their suggestions about coming to terms with solutions that are rooted in African experience, these articles resonate with the findings on local governance and local justice. They also provide further support to the main contention of this article, that the idea of 'working with the grain' can be translated into well-supported operational hypotheses.

contributing to the cost, but also to the somewhat broader set of goods and services with strong positive social externalities which are under-produced because of what are technically called information imperfections.

2 For a fuller discussion, see Booth (2008).

3 Those connected with 'grain' as in the seed of cereals like wheat or maize, for example.

4 And social networks can explain what it is sometimes supposed that only shared values can explain (Moore 1994). 


\section{References}

Acemoglu, D.; Johnson, S. and Robinson, J. (2005) 'Institutions as a Fundamental Cause of Long-Run Growth', in P. Aghion and S. Durlauf (eds), Handbook of Economic Growth, Amsterdam: Elsevier: 385-464

Berry, S. (1993) No Condition is Permanent: The Social Dynamics of Agrarian Change in SubSaharan Africa, Madison: University of Wisconsin Press

Boone, C. (2003) Political Topographies of the African State: Territorial Authority and Institutional Choice, New York: Cambridge University Press

Booth, D. (2008) A Research Design Fit for Purpose, Discussion Paper 3, London: Africa Power and Politics Programme

Bratton, M. and van de Walle, N. (1997) Democratic Experiments in Africa: Regime Transitions in Comparative Perspective, Cambridge: Cambridge University Press

Centre for the Future State (2010) An Upside Down View of Governance, Brighton: IDS

Collier, D.; Mahoney, J. and Seawright, J. (2004) 'Claiming Too Much: Warnings about Selection Bias', in H.E. Brady and D. Collier (eds), Rethinking Social Inquiry: Diverse Tools, Shared Standards, Lanham, MD: Rowman and Littlefield: 85-102

Crook, R. (1990) 'Politics, the Cocoa Crisis, and Administration in Côte d'Ivoire', Journal of Modern African Studies 28.4: 649-69

Crook, R. (1989) 'Patrimonialism, Administrative Effectiveness and Economic Development in Côte d'Ivoire', African Affairs 88: 205-28

Eisenstadt, S.N. (1972) Traditional Patrimonialism and Modern Neo-patrimonialism, London: Sage

Englebert, P. (2002) State Legitimacy and Development in Africa, Boulder, CO: Lynne Rienner

Evans, P.B. (2004) 'Development as Institutional Change: The Pitfalls of Monocropping and the Potentials of Deliberation', Studies in Comparative International Development 38.4: 30-52

George, A.L. and Bennett, A. (2005) Case Studies and Theory Development in the Social Sciences, Cambridge, MA: MIT Press

Gerring, J. (2007) Case Study Research: Principles and Practices, Cambridge: Cambridge University Press

Granovetter, M. (1985) 'Economic Action and Social Structure: The Problem of Embeddedness', American Journal of Sociology 91.3: 481-510
Greif, A. (2006) Institutions and the Path to the Modern Economy: Lessons from Medieval Trade, Cambridge: Cambridge University Press

Grindle, M. (2007) 'Good Enough Governance Revisited', Development Policy Review 25.5: 553-574

Grindle, M. (2004) 'Good Enough Governance: Poverty Reduction and Reform in Developing Countries', Governance: An International Journal of Policy, Administration, and Institutions 17.4: 525-48

Habyarimana, J.; Humphreys, M.; Posner, D.N. and Weinstein, J.M. (2009) Coethnicity: Diversity and the Dilemmas of Collective Action, New York: Russell Sage Foundation

Hedström, P. and Swedberg, R. (eds) (1998) Social Mechanisms: An Analytical Approach to Social Theory, Cambridge: Cambridge University Press

Hyden, G. (2008) Institutions, Power and Policy Outcomes in Africa, Discussion Paper 2, London: Africa Power and Politics Programme

Hyden, G. (2006) African Politics in Comparative Perspective, Cambridge: Cambridge University Press

Kelsall, T. (2009) Game-theoretic Models, Social Mechanisms and Public Goods in Africa: A Methodological Discussion, Discussion Paper 7, London: Africa Power and Politics Programme Kelsall, T. (2008) 'Going with the Grain in African Development?', Development Policy Review 26.6: 627-55

Khan, M.H. (2006) Governance, Economic Growth and Development since the 1960s: Background Paper for World Economic and Social Survey 2006, New York: UNDESA

Kohli, A. (2004) State-Directed Development: Political Power and Industrialization in the Global Periphery, Cambridge: Cambridge University Press

Leonard, D.K. and Straus, S. (2003) Africa's Stalled Development: International Causes and Cures, Boulder, CO: Lynne Rienner

Levine, V.T. (1980) 'African Patrimonial Regimes in Comparative Perspective', Journal of Modern African Studies 18.4: 657-73

Levy, B. (2010) Development Trajectories: An Evolutionary Approach to Integrating Governance and Growth, Economic Premise 15, Washington DC: World Bank

Médard,J.-F. (1982) 'The Underdeveloped State in Tropical Africa: Political Clientelism or NeoPatrimonialism?', in C. Clapham (ed.), Private Patronage and Public Power: Political Clientelism in the Modern State, London: Frances Pinter: 162-92 
Meisel, N. and Aoudia, J.O. (2008) Is 'Good Governance' a Good Development Strategy.?, Working Paper 58, Paris: Agence Française de

Développement, Département de la Recherche

Moore, M. (1994) 'How Difficult is it to Construct Market Relations? A Commentary on Platteau', Journal of Development Studies 30.4: 818-30

North, D.C.; Wallis, J.J. and Weingast, B.R. (2009) Violence and Social Orders: A Conceptual Framework for Interpreting Recorded Human History, Cambridge: Cambridge University Press

Olivier de Sardan, J.-P. (2008) Researching the Practical Norms of Real Governance in Africa, Discussion Paper 5, London: Africa Power and Politics Programme

Olivier de Sardan, J.-P. (2005) Anthropology and Development: Understanding Contemporary Social Change, London: Zed Books

Olson, M. (1993) 'Dictatorship, Democracy, and Development', American Political Science Review 87.3: 567-76

Ostrom, E. (1990) Governing the Commons: The Evolution of Institutions for Collective Action, Cambridge: Cambridge University Press

Posner, D.N. (2005) Institutions and Ethnic Politics in Africa, Cambridge: Cambridge University Press
Ragin, C.C. (1987) The Comparative Method: Moving Beyond Qualitative and Quantitative Strategies, Berkeley, CA: University of California Press

Rodrik, D. (ed.) (2003) In Search of Prosperity: Analytical Narratives of Economic Growth, Princeton NJ: Princeton University Press

Rodrik, D.; Subramanian, A. and Trebbi, F. (2004) 'Institutions Rule: The Primacy of Institutions over Geography and Integration in Economic Development', Journal of Economic Growth 9: 131-65

Sandler, T. (2001) Economic Concepts for the Social Sciences, Cambridge: Cambridge University Press

Shivakumar, S. (2005) The Constitution of Development: Crafting Capabilities for SelfGovernance, New York: Palgrave Macmillan Swidler, A. (1986) 'Culture in Action: Symbols and Strategies', American Sociological Review 51: 273-86

van Donge, J.K.; Henley, D. and Lewis, P. (2010) Tracking Development in Southeast Asia and SubSaharan Africa: The Primacy of Policy, Leiden: Tracking Development Projet 